Türk Turizm Araştırmaları Dergisi
2020,4(1): 686-698.

\title{
Online Yorumların Faydalı Bulunma Durumunun İncelenmesi: Konaklama İşletmeleri Üzerine Bir Araştırma*
}

Arş. Gör. Engin TENGİLiMOĞLU, Selçuk Üniversitesi, Beyşehir Ali Akkanat Turizm Fakültesi, Konya, e-posta: entengilimoğlu@selcuk.edu.tr ORCID: https://orcid.org/0000-0001-7080-6147

Prof. Dr. Yüksel ÖZTÜRK, Ankara Hacı Bayram Veli Üniversitesi, Turizm Fakültesi, Ankara, eposta: yuksel.ozturk@hbv.edu.tr ORCID: https://orcid.org/0000-0002-4320-5626

$\ddot{O} z$

Gelişen internet teknolojileri tüketicilerin turistik ürün satın alma davranışlarını köklü bir şekilde değiştirirken bilgi arama süreçlerinde online platformların önemli bir konuma gelmesini sağlamıştır. Tüketiciler tarafından online ortamlarda günlük olarak paylaşılan sayısız içerik neticesinde ise faydalı bilgilere ulaşmak zorlaşmış ve bu sorunu aşmak için yorum siteleri okuyucularına okumuş oldukları yorumları faydalı veya değil şeklinde değerlendirme imkanı sunmaya başlamıştır. Okuyucuların faydalı buldukları yorumlar hem tüketicilerin bilgi arama süresinin kısalmasını hem de satın alma karar süreçlerinin daha yüksek düzeyde etkilenmesini sağlamıştır. Faydalı yorumların sunmuş olduğu katkılar aynı zamanda araştırmacıların bir yorumu faydalı kılan özelliklerin neler olduğunu incelemesine neden olmuştur. Bu bağlamda çalışmanın amacı yorum, yorumcu ve yorumun bırakıldığı otele ilişkin hangi özelliklerin yorumun faydalı bulunma durumunu etkilediğinin tespit edilmesidir. Bu amaç doğrultusunda TripAdvisor sitesi üzerinde yer alan Antalya otelleri için bırakılmış 8,018 adet yorum indirilmiştir. Daha sonra lojistik regresyon modeli ile yorumların faydalı bulunma durumlarının tahmin edilmesine katkı sağlayan özellikler tespit edilmiştir. Sonuç olarak yorum puanı, yorum tarihi, yorumda resim paylaşımı, yorumcunun almış olduğu toplam faydalı oy sayısı, yorumcunun etki gücü ve yorumun bırakıldığı ilgili otelin toplam yorum sayısı yorumun faydalı bulunma durumunu etkileyen unsurlardır.

* Bu çalışma 16-19 Ekim 2019 tarihinde 20. Ulusal Turizm Kongresinde sunulan “Online Yorumların Faydalı Bulunma Durumunun İncelenmesi: Konaklama İşletmeleri Üzerine Bir Araştırma" isimli bildirinin genişletilmiş halidir.

Anahtar Kelimeler: Online Yorumlar, Faydalı Oy, Online Seyahat Acenteleri.

Makale Gönderme Tarihi: 02.11.2019

Makale Kabul Tarihi: 17.01.2020

\section{Önerilen Attf:}

Tengilimoğlu, E. ve Öztürk, Y. (2020). Online Yorumların Faydalı Bulunma Durumunun İncelenmesi: Konaklama İşletmeleri Üzerine Bir Araştırma, Türk Turizm Araştırmaları Dergisi, 4(1): 686-698.

(C) 2020 Türk Turizm Araştırmaları Dergisi. 


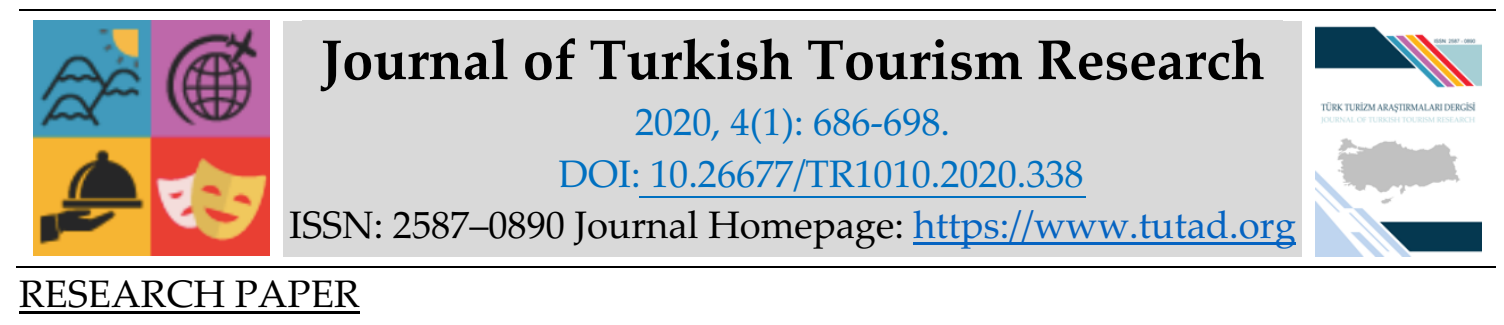

\title{
Investigating of Online Reviews Usefulness: A Research on Hospitality Industry
}

Research Assistant Engin TENGİLIMOĞLU, Selçuk University, Beyşehir Ali Akkanat Faculty of Tourism, Konya, e-mail: entengilimoğlu@selcuk.edu.tr

ORCID: https://orcid.org/0000-0001-7080-6147

Prof. Dr. Yüksel ÖZTÜRK, Ankara Hacı Bayram Veli University, Faculty of Tourism, Ankara, email: yuksel.ozturk@hbv.edu.tr

ORCID: https://orcid.org/0000-0002-4320-5626

\begin{abstract}
Emerging internet technologies have radically changed the way of purchasing tourism products and have made online platforms an important position especially for information search processes of the consumers. As a result of the numerous reviews shared daily by users in online environments, it has become difficult to access useful information for the consumers. Review sites start to offer to their users to vote the reviews useful or not to overcome this problem. Reviews that readers find useful, reduce consumers' information search time and contribute their purchasing decision processes. The contributions of useful reviews have also led researchers to examine what are the features that make a review useful. In this context, the purpose of the study is to determine which features of the review and the reviewer affect the useful vote of review. For this purpose, 8,018 Antalya hotels' reviews have been downloaded from TripAdvisor. Then, with the logistics regression model, features that contributed to estimating the usefulness of the reviews were identified. Consequently, the review score, the posting date of the review, the sharing of pictures in the review, the total number of useful votes received by the reviewer, the influence of the reviewer and the total number of reviews of the relevant hotel are factors that affect the usefulness of the review.
\end{abstract}

Keywords: Online Reviews, Useful Vote, Online Travel Agencies.

Received: 02.11.2019

Accepted: 17.01 .2020

\section{Suggested Citation:}

Tengilimoğlu, E. and Öztürk, Y. (2020). Investigating of Online Reviews Usefulness: A Research on Hospitality Industry, Journal of Turkish Tourism Research, 4(1): 686-698.

(C) 2020 Türk Turizm Araştırmaları Dergisi. 


\section{Gíriş}

Yaşanan teknolojik gelişmelerle birlikte internetin yaygınlaşması ve internet kullanıcılarının sayıca artması sonucunda internet üzerinden yapılan alışverişler hem günlük yaşantımızın (Hong vd., 2017) hem de ekonominin (Liang vd., 2019) önemli bir parçası haline gelmiştir. Tüketicilerin, satın alma kararlarında önceki tüketicilerin düşüncelerine duydukları ihtiyaç ise kullanıcılara yorum imkanı sunan online platformların yayılmasını sağlamıştır (Karimi ve Wang, 2017). Böylece tüketiciler ürünlere ilişkin sadece tedarikçilerin sunmuş oldukları ürün bilgilerini değil aynı zamanda daha önceki tüketicilerin deneyimlerini de inceleme fırsatına kavuşmuştur (Akgöz ve Tengilimoğlu, 2015; Ak ve Kızılırmak, 2019). Özellikle turizm sektöründe önceden değerlendirilmesi güç olan soyut ürünler sunulması (Hu ve Chen, 2016) tüketicilerin belirsizliği azaltmak adına (Hong vd., 2017) kendilerine ürünlerin hem olumlu hem de olumsuz yönlerine dair bilgiler sunan (Filieri vd., 2018) online tüketici yorumlarına daha fazla önem vermesine neden olmuştur (Liu ve Park, 2015; Ak ve Dinçer, 2019).

Online yorumların artan önemi neticesinde, tüketicilere yorum imkanı sunan online turizm platformları yaygınlaşmaya başlamış (Tengilimoğlu vd., 2017; Kozak ve Cingi, 2019) ve tüketicilerin turizm ürünlerine ilişkin deneyim ve düşüncelerini online ortamlarda paylaşmaları global bir trend halini almıştır (Wong ve Qi, 2017). Günlük olarak daha fazla tüketicinin paylaşımda bulunması sonucunda online ortamlarda tüketiciler açısından değerlendirilmesi neredeyse mümkün olmayan (Huang vd., 2015) aşırı bilgi sorunu oluşmuştur (Hu vd., 2017). Oluşan aşırı bilgi tüketicilerin bilgiye ulaşmalarını kolaylaştırırken (Balouchi vd., 2017; Çetinkaya ve Şahbaz, 2019) faydalı bilgileri tespit etmelerini de zorlaştırmıştır (Filieri, Raguseo vd., 2018). Tüketiciler ise satın alma kararlarında kendilerine yol gösterecek olan faydalı bilgileri aramaktadır (Karimi ve Wang, 2017). Tüketicilerin oluşan aşırı bilgi içerisinden makul bir zaman içerisinde faydalı olanlara ulaşma istekleri (Hu vd., 2017) beraberinde online platformların kullanıcılarına okumuş oldukları yorumlara ilişkin değerlendirme imkanı sunmasına neden olmuştur (Liang vd., 2019). Bu bağlamda geliştirilen "faydalı oy" uygulaması yorumun algılanan değerini ölçmek için yorum siteleri tarafından yaygın bir şekilde kullanılmaktadır (Eslami vd., 2018). Yorumların almış oldukları faydalı oy sayıları okuyucuların fazla sayıdaki yorum arasından faydalı olana ulaşmasında önemli bir rol üstlenmektedir (Liu ve Park, 2015).

Bu çalışmada tüketicilerin bilgi arama süresini önemli ölçüde kısaltan (Eslami vd., 2018) faydalı yorumlar incelenmektedir. Bu bağlamda yorumların faydalı oy almasını etkileyen unsurlar ilgili literatür yardımı ile tespit edilerek araştırmanın kuramsal çerçevesi oluşturulmuştur. Daha sonra yorumlara ilişkin hangi özelliklerin yorumun almış olduğu faydalı oyu tahmin etme konusunda katkı sağladığı kurulan lojistik regresyon modeli ile tespit edilerek önerilere yer verilmiştir.

\section{KURAMSAL ÇERÇEVE}

Online yorumların değerinin ölçülmesinde en sık kullanılan yöntem faydalı oy uygulamasıdır (Eslami vd., 2018). Günümüzde birçok online seyahat sitesi tüketiciler tarafından bırakılan yorumların okuyucular tarafindan faydalı bulunup bulunmama durumlarının değerlendirilmesine olanak tanımaktadır (Huang vd., 2015). Böylece tüketiciler tarafından oluşturulan sayısız yorum içerisinden faydalı olanların belirlenerek okuyucuların ihtiyaç duydukları doğru bilgilere kolayca ulaşması sağlanmaktadır (Eslami vd., 2018). Bir yorumun faydalı oy alması; yorumun (1) okunduğunu, (2) okuyan tüketiciler için karar süreçleri açısından değerli bilgiler içerdiğini, (3) diğer yorumlarla kıyaslandığında daha bilgilendirici niteliğe sahip olduğunu (Hu ve Chen, 2016), (4) ilgili ürünün kalite ve performansı hakkında daha anlaşılır 
bilgiler içerdiğini (Filieri, Raguseo vd., 2018) ve (5) tüketici kararını etkilediğini göstermektedir (Lee vd., 2018).

Faydalı yorumlar tüketicilerin bilgi arama sürecini kısaltarak (Eslami vd., 2018) sunulan hizmete ilişkin özelliklerin daha iyi anlaşılmasına olanak tanımaktadır (Liu ve Park, 2015). Ayrıca online satıcıların kullanıcılarına daha yüksek değer yaratarak (Karimi ve Wang, 2017) kullanıcı memnuniyetini ve sadakatini arttırıp (Eslami, vd., 2018) site üzerinde gerçekleşen trafiğin yoğunlaşmasını sağlamaktadır (Hu ve Chen, 2016). Tedarikçilere ise kendi ürünleri hakkında tarafsız değerlendirmeler sunarak (Hu ve Chen, 2016) tüketicilerin hizmet kalitesini nasıl değerlendirdiği (Filieri, vd., 2018) ve hangi bilgilere önem verdiği konusunda ipuçları vermektedir (Liu ve Park, 2015).

Faydalı yorumların okuyucularda güven oluşturarak (Liu ve Park, 2015), karar süreçlerini daha yüksek düzeyde etkilediği (Eslami vd., 2018) ve böylece online satışların artmasını sağladığı da bilinmektedir (Hong vd., 2017). Bu bağlamda bir yorumu faydalı kılan özelliklerin tespit edilmesi özellikle soyut ürünler sunan turizm sektörü açısından büyük önem arz etmektedir (Filieri, 2018). Faydalı yorumların turizm sektöründe önemli bir konu haline gelmesi konuya ilişkin akademik camiada da ilginin artmasını sağlamıştır (Filieri, Raguseo vd., 2018). Yapılan çalışmalarda anket yöntemi (Filieri vd., 2018) veya yorum sitelerinde yer alan faydalı oy sayıları (Hu ve Chen, 2017) olmak üzere iki farklı veri kaynağının kullanıldığı görülmektedir. Faydalı oy sayılarının veri olarak kullanıldığı çalışmalarda yoruma ilişkin sayısal özellikler için nicel yöntemler (Huang, vd., 2015) yorum metinlerinin anlaşılması için ise metin madenciliği tekniklerinin (Malik ve Hussain, 2018) kullanıldığı bilinmektedir. Her iki yöntemi bir arada kullanan daha kapsamlı çalışmalarda bulunmaktadır (Liang vd., 2019).

Tablo 1 Faydalı Oyu Etkileyen Faktörler

\begin{tabular}{|c|c|c|c|}
\hline Kategorileri & Değişkenler & Açıklama & Kullanıldığı Çalışmalar \\
\hline $\begin{array}{l}\text { Bağımlı } \\
\text { Değişken }\end{array}$ & Yorum Faydalı Oyu & $\begin{array}{l}\text { Yorumun aldığ faydalı oy } \\
\text { sayısı }\end{array}$ & Bütün Çalışmalar \\
\hline \multirow{5}{*}{$\begin{array}{l}\text { Yorumla ilgili } \\
\text { Faktörler }\end{array}$} & Yorum Puanı & Yorumun puanı & $\begin{array}{l}\text { (Liu ve Park, 2015; Zhou ve } \\
\text { Guo, 2019; Liang vd., 2019) }\end{array}$ \\
\hline & Yorum Uzunluğu & $\begin{array}{l}\text { Yorumda kullanılan kelime } \\
\text { sayısı }\end{array}$ & $\begin{array}{l}\text { (Liu ve Park, 2015; Zhou ve } \\
\text { Guo, 2019) }\end{array}$ \\
\hline & $\begin{array}{l}\text { Yorum Başlığının } \\
\text { Uzunluğu }\end{array}$ & $\begin{array}{l}\text { Başlıkta kullanılan kelime } \\
\text { sayısı }\end{array}$ & Bu çalışma \\
\hline & Yorum Tarihi & Yorumun bırakıldığı ay & (Singh vd., 2017; Wu, 2017) \\
\hline & Resim Paylaşımı & Yorumda birakılan resim & (Filieri, Raguseo vd., 2018) \\
\hline \multirow{3}{*}{$\begin{array}{l}\text { Yorumcuyla } \\
\text { İlgili Faktörler }\end{array}$} & $\begin{array}{l}\text { Yorumcunun } \\
\text { Uzmanlığ } 1\end{array}$ & $\begin{array}{l}\text { Yorumcu tarafından } \\
\text { birakılan toplam yorum } \\
\text { sayısı }\end{array}$ & $\begin{array}{l}\text { (Huang vd., 2015; Zhou ve } \\
\text { Guo, 2019) }\end{array}$ \\
\hline & $\begin{array}{l}\text { Yorumcunun Toplam } \\
\text { Faydalı Oyu }\end{array}$ & $\begin{array}{l}\text { Yorumcunun aldığ toplam } \\
\text { faydalı oy sayısı }\end{array}$ & $\begin{array}{l}\text { (Huang vd., 2015; Liang } \\
\text { vd., 2019) }\end{array}$ \\
\hline & Yorumcunun Etkisi & $\begin{array}{l}\text { Toplam faydalı oyun toplam } \\
\text { yorum sayısına bölümü }\end{array}$ & (Huang vd., 2015) \\
\hline $\begin{array}{l}\text { Otel ile İlgili } \\
\text { Faktörler }\end{array}$ & $\begin{array}{l}\text { Otelin Toplam Yorum } \\
\text { Sayıs }\end{array}$ & $\begin{array}{l}\text { Otel için bırakılmış toplam } \\
\text { yorum sayısı }\end{array}$ & Bu çalışma \\
\hline
\end{tabular}

Birçok çalışmada yorumların faydalı oylarını incelemek için yorum ve yorumcu özellikleri ele alınmıştır (Hong vd., 2017). Yoruma ilişkin özelliklerden yorum uzunluğu (Zhou ve Guo, 2019), 
yorum puanı (Liang vd., 2019), yorum tarihi (Wu, 2017), yorumda resim paylaşımı (Filieri, Raguseo vd., 2018) yorumun almış olduğu faydalı oyu incelemek için sık kullanılırken yorumcuya ait özelliklerden bırakılan toplam yorum sayısı (Huang vd., 2015), alınan toplam faydalı oy sayısı (Liang vd., 2019) ve yorumcunun etkisi (Huang vd., 2015) ele alınmaktadır. Tablo 1 ilgili literatür dahilinde araştırmada ele alınan değişkenleri vermektedir.

Tablo 1'de yer verilen araştırma değişkenlerinin bir bütün halinde faydalı oy üzerine etkisini ölçen bir çalışmaya rastlanılamamıştır. Diğer çalışmalardan farklı olarak başlık uzunluğu ve otelin sahip olduğu toplam yorum sayısı da yorumların faydalı bulunma durumunu etkileyebilecek değişkenler olarak modele eklenmiştir. Bu bağlamda faydalı yorumlara ilişkin literatür dahilinde Şekil 1'de verilen model geliştirilmiştir.

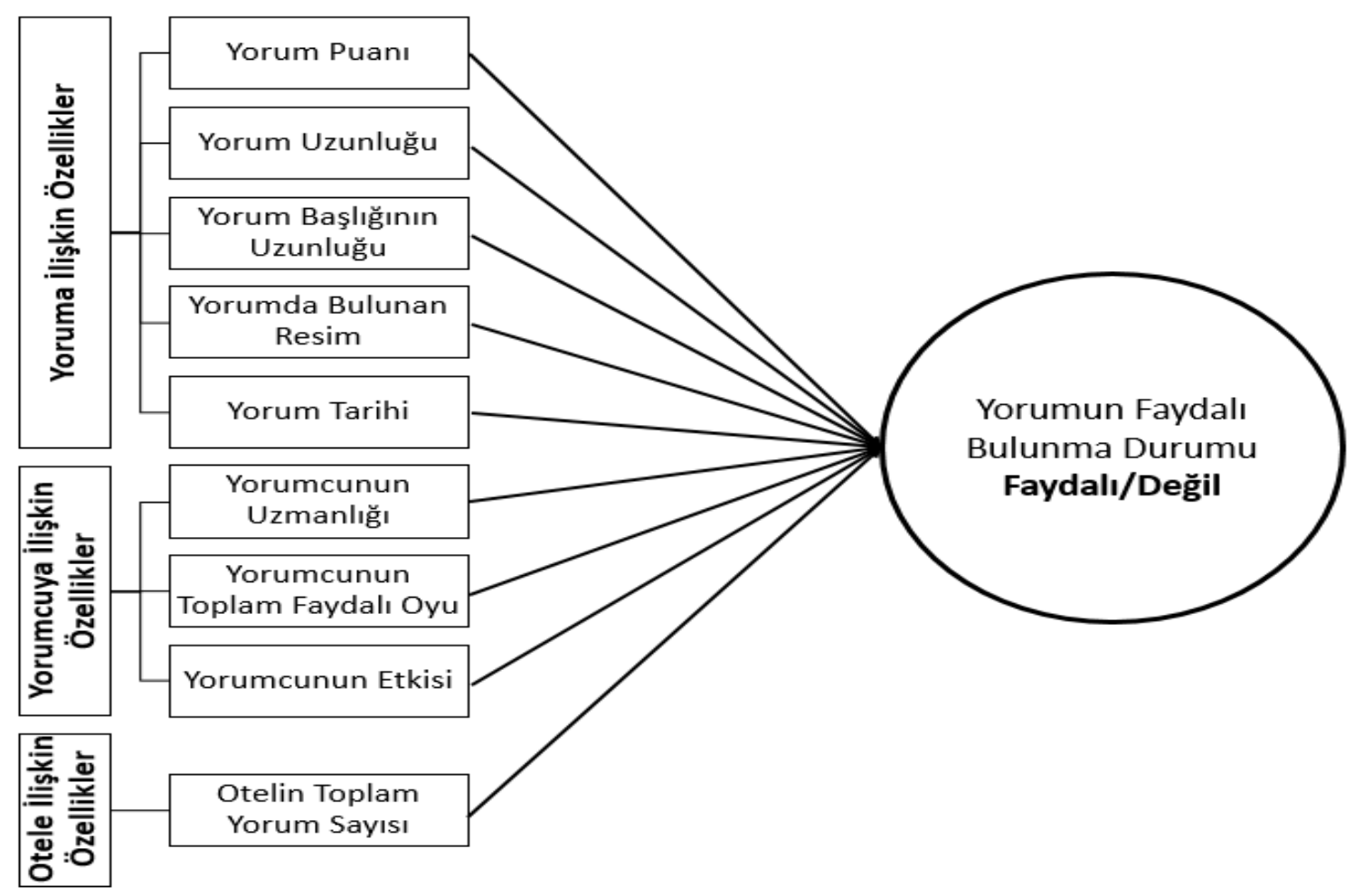

Şekil 1 Araştırma Modeli

\section{YÖNTEM}

Tüketicilerin faydalı yorumlara daha fazla güven duymaları (Liu ve Park, 2015) ve satın alma kararlarında faydalı yorumlardan daha fazla etkilenmeleri (Eslami, 2018) paylaşılan çok sayıda yorum içerisinden (Hu vd., 2017) hangilerinin faydalı bulunduğunun tespit edilmesi konusunun akademik camiada da yankı uyandırmasına neden olmuştur. Bu çalışmada da yorumların okuyucular tarafından faydalı bulunmasını sağlayan özellikler; yorum, yorumcu ve yorum bırakılan otel olmak üzere üç başlıkta incelenmiştir. Faydalı yorum araştırmalarında yorum, yorumcu ve diğer özellikleri ele alan kapsayıcı çalışmaların daha doğru sonuçlar vereceği düşünülmektedir (Huang, 2015). 
Çalışmada veri olarak TripAdvisor sitesinde yer alan 42 adet 5 yıldızlı Antalya oteli için 2018 yılı içerisinde Türkçe olarak bırakılmış toplam 8.018 yorum kullanılmıştır. Yorumlar paket program aracıllğı ile 2019'un Şubat ayı içerisinde indirilmiştir.

Öncelikle çalışmaya dahil edilen yorumların tanımlayıcı verilerine yer verilmiş ve daha sonra hangi yorum özelliklerinin yorumun faydalı bulunma durumunun tahmin edilmesine katkı sağladığını tespit etmek için lojistik regresyon modeli kurulmuştur. Şekil 2'de çalışmada veri olarak kullanılan örnek bir yoruma yer verilerek kullanılan değişkenler numaralandırılmıştır.



Şekil 2 Örnek Yorum

Çalışmada kullanılan değişkenler; (1) yorum tarihi, (2) yorumcunun toplam faydalı oy sayısı, (3) yorumcunun toplam katkısı, (4) yorum puanı, (5) yorum başlığı, (5) yorum metni, (7) yorum faydalı oyu (8) resimdir. Bunlar dışında yorumun bırakıldığı otelin sahip olduğu toplam yorum sayısı da ele alınmıştır. Araştırmada kullanılan yorumcunun etkisi değişkeni ise yorumcunun almış olduğu faydalı oy sayısının bıraktığı yorum sayısına bölümü ile hesaplanmıştır (Huang vd., 2015).

Başlık ve yorum uzunlukları literatürde yaygın olarak kelime sayısı ile ölçülmektedir (Liu ve Park, 2015; Zhou ve Guo, 2019. Bu çalışmada da yorum içerisinde geçen kelime sayıları başlık ve yorum uzunluğunu ölçmede kullanılmıştır.

\section{BULGULAR}

Çalışmada ele alınan yorumların aylara göre dağılımları, faydalı bulunma durumları ve içerisinde resim paylaşılma oranları aşağıda yer alan Grafik 1 ve Tablo 2 de verilmiştir. Ele alınan yorumlar 42 adet 5 yıldızlı otel için 2018 yılı içerisinde bırakılmış bütün yorumları kapsamaktadır. Böylece çalışmada kullanılan örneklem yönteminin, yorumların aylara göre dağılımları üzerindeki olumsuz etkisinin önüne geçilmiştir. 


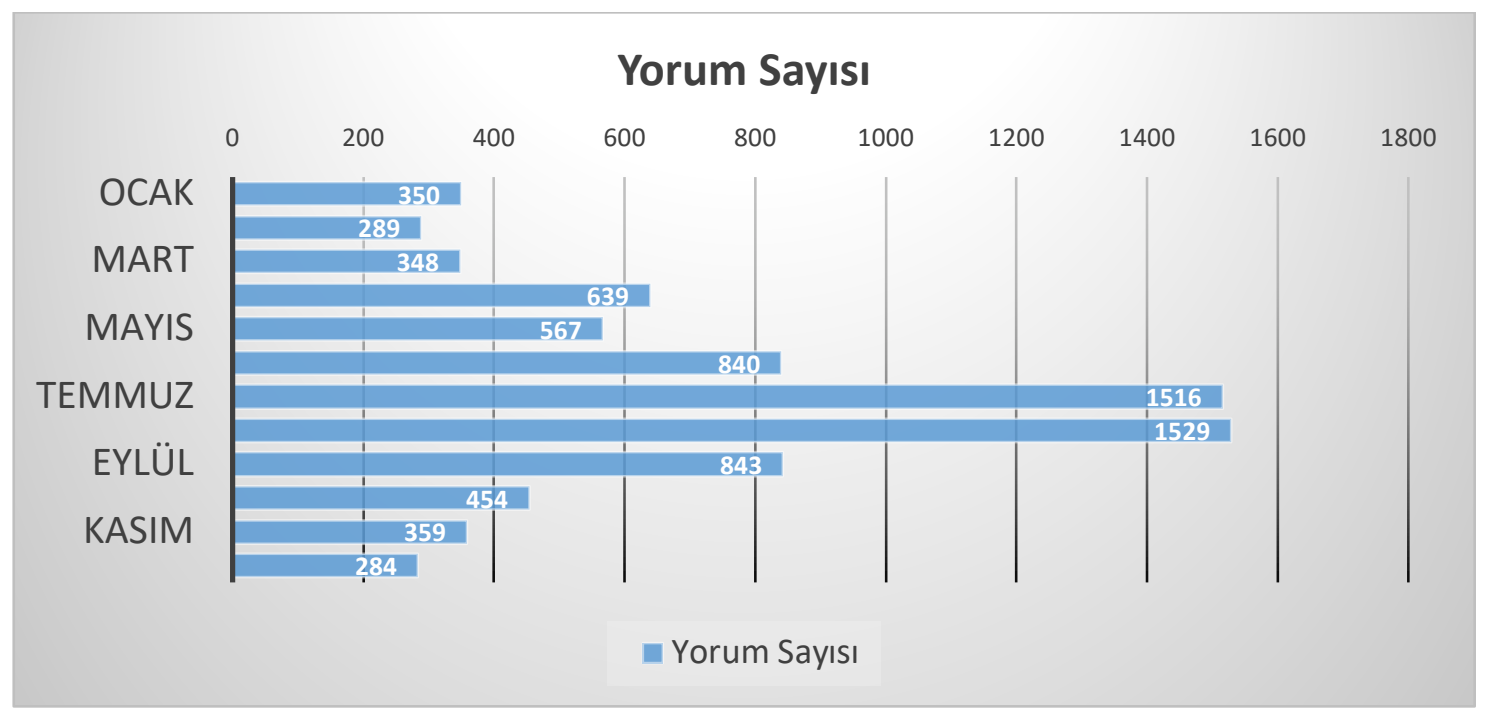

Grafik 1 Aylara Göre Bırakılan Yorum Sayıları

Genel olarak yorumların Antalya bölgesi açısından yüksek sezonu ifade eden yaz ve bahar aylarında sayıca arttığı görülmektedir.

Tablo 2 Yorumlara İlişkin Dağılımlar

\begin{tabular}{lllc}
\hline Kriter & Cevap & n & \% \\
\hline \multirow{2}{*}{ Faydalı Bulunma durumu } & Faydalı & 1665 & 20,8 \\
\cline { 2 - 4 } & Değil & 6353 & 79,2 \\
\hline \multirow{2}{*}{ Resim Paylaşılma Durumu } & Var & 1256 & 15,7 \\
\cline { 2 - 4 } & Yok & 6762 & 84,3 \\
\hline Toplam & & 8018 & 100 \\
\hline
\end{tabular}

Çalışmada ele alınan yorumların \%20,8 ile 1.665 'i en az bir okuyucu tarafından faydalı bulunurken $\% 79,2$ ile 6.353'ü faydalı bulunmamıştır. Yorumların \%15,7 ile 1.256'sında resim paylaşılırken $\% 84,3$ ile 6.762 'sinde resim paylaşılmamıştır.

Yorumların "faydalı" veya "değil" olarak iki sınıfa ayrıştırılabilmesi, lojistik regresyon yönteminin normal dağılım şartı taşımaması ve bağımlı değişken üzerinde hem sürekli hem de kategorik değişkenlerin etkisini ölçebiliyor olması çalışmada lojistik regresyon modelinin tercih edilmesinde etkili olmuştur. Lojistik regresyon; bağımlı değişkenin iki seçme düzeyli kategorik olduğu durumlarda, sürekli ya da kategorik olarak ölçülmüş bir veya birden fazla bağımsız değişken yardımıyla, bağımlı değişkenin tahmin edilmesinde kullanılan bir tekniktir (İslamoğlu ve Alnıaçık, 2014).

Lojistik regresyon ilk olarak bağımsız değişkenleri kullanmadan gözlemlerin her birini en yüksek frekansa sahip olan sınıfa atayarak basit bir tahminde bulunur. Bu tahmin ayn zamanda kurulan modelin tahmin başarısını değişken kullanılmadan yapılan tahminle karşılaştırma imkanı sunarak modelin başarısı hakkında da bilgi vermektedir. 
Tablo 3 Başlangıç Modeli Sınıflandırma Tablosu

\begin{tabular}{cl|c|c|c}
\hline \multirow{2}{*}{ Gözlenen } & \multicolumn{3}{|c}{ Tahmin Edilen } \\
\cline { 3 - 4 } & & \multicolumn{2}{|c}{ Yorum Faydalı Oy } & \multirow{2}{*}{ Doğruluk Yüzdesi } \\
\cline { 3 - 4 } & & Faydalı & Değil & \\
\hline \multirow{2}{*}{ Yorum Faydalı Oy } & 0 & 1665 & 0 \\
\hline & Faydalı & 0 & 6353 & 100,0 \\
\hline & Değil & 0 & $\mathbf{7 9 , 2}$ \\
\hline
\end{tabular}

Araştırmada ele alınan yorumların \%79,2'sinin "değil" sınıfında yer alması hiçbir bağımsız değişken kullanılmadan bütün yorumların faydalı olmadığının tahmin edildiği başlangıç modelinin \%79,2 oranında doğru tahminde bulunacağı anlamına gelmektedir.

Tablo 4 bağımlı değişkenlerle birlikte ele alınan yeni model ile bağımlı değişken kullanılmayan başlangıç modeli tahminleri arasında anlamlı bir fark olup olmadığını göstermektedir. Bu fark aynı zamanda modelin anlamlı olup olmadığının belirlenmesinde de kullanılmaktadır (İslamoğlu ve Alnıaçık, 2014).

Tablo 4 Omnibus Anlamlllık Testi

\begin{tabular}{lllll}
\hline & Model & Chi-square & df & Sig. \\
\hline \multirow{3}{*}{ Step 1 } & Step & 4129,028 & 19 &, 000 \\
\cline { 2 - 5 } & Block & 4129,028 & 19 &, 000 \\
\cline { 2 - 5 } & Model & 4129,028 & 19 &, 000 \\
\hline
\end{tabular}

Tablo 4 kurulan lojistik regresyon modelinin anlamlı olduğunu göstermektedir $(p<0,05)$. Bu durum kurulan modelin hiçbir değişken kullanılmayan başlangıç modelinden daha başarılı olduğu şeklinde yorumlanabilir. Özetle kurulan model hiçbir değişken kullanılmadan yapılan tahmin modelinden daha yüksek oranda doğruluk yüzdesine sahiptir.

Tablo 5 Model Özet Tablosu

\begin{tabular}{l|r|r|r}
\hline \multirow{2}{*}{ Step 1 } & \multicolumn{1}{|c|}{-2 Log likelihood } & Cox \& Snell R Square & Nagelkerke R Square \\
\cline { 2 - 4 } & $4062,751^{\mathrm{a}}$ &, 402 &, 629 \\
\hline
\end{tabular}

Tablo 5 bağımlı değişkendeki varyansın ne kadarının kurulan tahmin modeli ile açıklandığını göstermektedir. Literatürde bu oranı ifade eden iki yöntem bulunmaktadır. Genel olarak çalışmalarda iki yöntem ile hesaplanmış değerlerin arasında kalan oran modelin açıklama oranı olarak ele alınmaktadır. Bu bağlamda model yorumların faydalı bulunma durumundaki varyansın \%40,2'si ile \%62,9'u arasındaki bir kısmını açıklamaktadır.

Tablo 6 Modelin Sinıflandırma Tahmin Tablosu

\begin{tabular}{ll|c|c|c}
\hline \multirow{2}{*}{ Gözlenen } & \multicolumn{3}{c}{ Tahmin Edilen } \\
\cline { 3 - 4 } & & \multicolumn{2}{c}{ Yorum Faydalı Oy } & \multirow{2}{*}{ Doğruluk Yüzdesi } \\
\cline { 3 - 4 } & & Faydalı & Değil & \\
\hline \multirow{2}{*}{ Yorum Faydalı Oy } & Faydalı & 1045 & 620 & 62,8 \\
\cline { 2 - 4 } & Değil & 377 & 5976 & 94,1 \\
\hline \multicolumn{2}{c}{ Ortalama Doğruluk Yüzdesi } & & $\mathbf{8 7 , 6}$ \\
\hline
\end{tabular}


Model, hiçbir değişken kullanılmadan yorumların hepsinin faydalı değil olarak tahmin edildiği başlangıç modelinden $(\% 79,2)$ daha yüksek bir tahmin gücüne $(\% 87,6)$ sahiptir. Faydalı yorumların doğru tahmin oranı (duyarlılık) \%62,8, faydalı olmayanların doğru tahmin oranı ise (özgüllük) \%94,1'dir.

Tablo 7 kurulan modelde yer alan bağımlı değişkenlere ilişkin hesaplanan katsayıları ve bu katsayıların anlamlı olup olmadığını gösteren $\mathrm{p}$ değerlerini vermektedir.

Tablo 7 Modelde Yer Alan Değişkenlerin Katsayı Tablosu

\begin{tabular}{|c|c|c|c|c|c|c|}
\hline Bağımsız Değişkenler & B & S.E. & Wald & df & Sig. & $\operatorname{Exp}(B)$ \\
\hline Yorum Puanı & 223 & ,040 & 30,579 & 1 & ,000 & 1,250 \\
\hline Yorum Uzunluğu &,- 070 & 041 & 2,888 & 1 & 089 & ,933 \\
\hline Başlık Uzunluğu &,- 063 & 039 & 2,585 & 1 & 108 & ,939 \\
\hline Yorumcunun Uzmanlı̆̆1 & ,109 & ,071 & 2,335 & 1 & 127 & 1,115 \\
\hline $\begin{array}{l}\text { Yorumcunun Toplam } \\
\text { Faydalı Oyu }\end{array}$ &,- 172 & ,073 & 5,484 & 1 & ,019 & 842 \\
\hline Yorumcunun Etkisi & $-3,136$ & 092 & 1158,745 & 1 & 000 & ,043 \\
\hline Otelin Toplam Yorum Sayısı & 420 & 041 & 106,288 & 1 & , 000 & 1,522 \\
\hline Resim Yok & ,943 & ,103 & 84,585 & 1 & , 000 & 2,567 \\
\hline Yorum Tarihi & & & 519,197 & 11 & ,000 & \\
\hline Şubat &,- 942 & 2,336 & , 163 & 1 & ,687 & ,390 \\
\hline Mart & 13,038 & 1683,19 & , 000 & 1 & ,994 & 459374,89 \\
\hline Nisan & $-1,236$ & 2,190 & ,318 & 1 &, 573 & ,291 \\
\hline Mayıs & $-7,469$ & 1,917 & 11,383 & 1 & ,001 & ,002 \\
\hline Haziran & $-11,436$ & 1,835 & 38,842 & 1 & , 000 & , 000 \\
\hline Temmuz & $-14,619$ & 1,845 & 62,790 & 1 & , 000 & , 000 \\
\hline Ăgustos & $-14,180$ & 1,843 & 59,204 & 1 & ,000 & , 000 \\
\hline Eylül & $-14,823$ & 1,847 & 64,394 & 1 & ,000 &, 000 \\
\hline Ekim & $-6,967$ & 1,850 & 65,456 & 1 & ,000 & , 071 \\
\hline Kasım & $-5,757$ & 1,850 & 55,273 & 1 & , 000 & ,093 \\
\hline Aralık & $-4,729$ & 1,850 & 55,063 & 1 & , 000 & , 107 \\
\hline Constant & 14,273 & 1,839 & 60,223 & 1 & ,000 & 1580875,006 \\
\hline
\end{tabular}

a. Variable(s) entered on step 1: Yorum Puanı, Yorum Uzunluğu, Başlık Uzunluğu, Yorumcunun Uzmanlığı, Yorumcunun Toplam Faydalı Oyu, Yorumcunun Etkisi, Otelin Toplam Yorumu, Resim Sayısı, Yorum Tarihi.

Tablo 7 incelendiğinde, yorum puanının, yorumcunun sahip olduğu toplam faydalı oyun, yorumcunun etki gücünün, otelin almış olduğu toplam yorum sayısının, paylaşılan resmin ve yorum tarihinin yorumun faydalı bulunup bulunmama durumunu tahmin etmek konusunda katkı sağlayan önemli değişkenler olduğu söylenebilir.

Katsayılar tablosundaki önemli verilerden birisi de $\operatorname{Exp}(B)$ değerleridir. Bu değerler, diğer değişkenler sabitken bağımsız değişkende ortaya çıkan bir birimlik değişimin ortaya çıkması beklenen durumun (Yorumun Faydalı Bulunmaması) ihtimalindeki (Odds) oransal değişimi ifade etmektedir. $\operatorname{Exp}(B)$ değerinin 1'den büyük olması bağımlı değişken ile bağımsız değişkenin olasılığı arasındaki doğru orantıyı ifade ederken 1'den küçük olması ise ters orantıyı 
göstermektedir. Bu bilgiler ışığında yorum puanının $(1,250)$ ve otelin sahip olduğu toplam yorum sayısının $(1,522)$ artması durumunda yorumun faydalı bulunmama ihtimalinin de arttığını söyleyebiliriz. Yorumcunun sahip olduğu toplam faydalı oy $(0,842)$ ve yorumcunun etkisi $(0,043)$ arttığında ise yorumun faydalı bulunmama ihtimali önemli ölçüde azalmaktadır. Model içerisinde yer alan yorum uzunluğu, başlık uzunluğu, yorumcunun uzmanlığı gibi değişkenler ise bağımlı değişkeni tahmin etme konusunda katkı sağlamamaktadır $(\mathrm{p}<0,05)$.

Bağımlı değişken üzerinde etkili olan kategorik değişkenlerin yorumlanmasında ilgili sınıfın referans sınıfı ile karşılaştırması yapılmaktadır. Resim paylaşımı ve yorum tarihi yorumun faydalı bulunma durumunu tahmin etme konusunda anlamlı katkı sağlamaktadır $(p<0,05)$. Resim paylaşılmayan yorumların faydalı bulunmama ihtimali resim paylaşılan yorumlara göre 2,567 kat daha fazladır. Nisan ve sonraki aylarda paylaşılan yorumların Ocak ayında paylaşılan yorumlara göre faydalı bulunmama ihtimali oldukça azdır.

\section{SONUÇ ve ÖNERILLER}

İnternet ortamında paylaşılan yoğun içerikler neticesinde oluşan aşırı bilgi sorunu (Dirsehan, 2016) online platformların faydalı bilgilere ulaşılmasını kolaylaştırmak adına kullanıcılarına yorumların "faydalı" olup olmadığını değerlendirme imkanı sunmasına neden olmuştur (Huang vd., 2015). Faydalı yorumların bilgi arama süresini kısaltarak tüketici karar sürecini daha yüksek düzeyde etkilemesi (Eslami vd., 2018) ve tedarikçiler açısından önemli geri bildirimler içermesi (Filieri vd., 2018) yoruma ilişkin hangi özelliklerin yorumun faydalı bulunmasına katkı sağladığı konusuna merak duyulmasını sağlamıştır (Liu ve Park, 2015). Bu çalışmada da yorumların faydalı bulunma durumları yorum özelliklerini, yorumcu özelliklerini ve yorumun bırakıldığı otelin özelliklerini ele alan bir lojistik regresyon modeli ile incelenmiştir. Sonuç olarak yorum özelliklerinden yorum puanının, yorumda resim paylaşımının ve yorum tarihinin; yorumcu özelliklerinden yorumcunun bugüne kadar almış olduğu toplam faydalı oy sayısının, yorumcunun toplam faydalı oy sayısının bıraktığı toplam yorum sayısına bölümünü ifade eden yorumcunun etkisinin ve otel özelliklerinden ise otelin sahip olduğu toplam yorum sayısının yorumun faydalı bulunma durumunu tahmin etmede önemli değişkenler olduğu tespit edilmiştir.

İlgili literatürde yorum uzunluğunun yorumun faydalı bulunma durumunu etkilediğine (Liu ve Park, 2015; Liang vd., 2019) ilişkin sonuçlar bulunmasına karşın bu araştırmada anlamlı bir sonuca ulaşılamamıştır. Yorumun başlık uzunluğu ise daha önceki çalışmalarda rastlanılamamış bir değişkendir. Yapılan analizde anlamlı bir etkiye sahip olmadığı sonucuna ulaşılmıştır. Yorumcunun bırakmış olduğu toplam yorum sayısı ile ölçülen yorumcunun uzmanlığı da faydalı yorumu tahmin etme konusunda katkı sağlamayan değişkenlerdendir. Huang ve arkadaşları da (2015) yorumcunun uzmanlığı ile faydalı oy arasında bir ilişki tespit edememişlerdir.

Yorum puanına ilişkin literatürde çelişkili sonuçlar bulunmaktadır. Hong ve arkadaşları (2017) yorum puanının faydalı oyu etkilemediğini belirtirken Karimi ve Wang (2017) negatif yönlü, Pan ve Zhang (2011) pozitif yönlü bir etkiden bahsetmektedir. Park ve Nicolau (2015) ise çok düşük ve çok yüksek puanların faydalı algılandığını ifade etmektedir. Bu araştırmada ise Karimi ve Wang'ın çalışmasına benzer bir şekilde yorum puanının artması ile yorumun faydalı bulunma ihtimalinin azalacağı tespit edilmiştir. Fakat ilgili yazında genel kanı Park ve Nicolau'nun belirttiği gibi U biçiminde bir ilişkinin olduğu yönündedir. Okuyucular çok düşük ve çok yüksek puanlı yorumları daha faydalı bulmaktadır.

Fang ve arkadaşları (2016) paylaşılan resimlerin daha ikna edici olduğunu belirtmektedir. Filieri, Raguseo ve arkadaşları (2018) ise paylaşılan resimlerin yorumun faydalı bulunmasında etkili 
olduğunu tespit etmişlerdir. Bu çalışmada da benzer şekilde içerisinde resim bulunan yorumların faydalı bulunma olasılığının daha yüksek olduğu tespit edilmiştir.

Yorumun bırakılma tarihi de ilgili yazında sık ele alınan konulardan birisidir. Daha önce bırakılan yorumların daha uzun bir süre yayında kalmasından dolayı genel kanı daha fazla faydalı oya sahip olacağı yönündedir (Lee vd., 2018). Zhou ve Guo (2019) ise yorumcunun popülaritesi arttığında yorumun daha çok görüntüleneceği için yorum tarihinin negatif etkisinin de azalacağını belirtmektedir. Bu düşünceden yola çıkarak Antalya bölgesinde yüksek sezonu ifade eden aylarda artan satışlarla birlikte yorumların daha çok kişi tarafından okunduğu ön görüsünün de benzer şekilde yorum tarihinin negatif etkisini azalttığ düş̧ünülebilir. Bu araştırmada Lee ve arkadaşlarının (2018) aksine Mayıs ve sonraki aylarda bırakılmış yorumların daha önceki aylarda bırakılan yorumlara göre faydalı bulunma ihtimali daha yüksek çıkmıstır. Bu durum Antalya için yüksek sezonu ifade eden o aylarda yorumların daha fazla kullanıcı tarafından okunması ve faydalı bulunması ile açıklanabilir.

Son olarak otelin sahip olduğu toplam yorum sayısının otele ilişkin yorumun faydalı bulunma ihtimali üzerine etkisi incelenmiştir. Beklenenin aksine otelin daha fazla yoruma sahip olması yorumun faydalı bulunma ihtimalini azaltmaktadır. Bu sonuç daha çok yorum bırakılması ile yorum sırasının kısa sürede değiştiği ve yorumların faydalı oy alacak kadar ilk sayfada kalamadığı şeklinde yorumlanabilir. Benzer şekilde Zhou ve Guo da (2019) yorumların arka sıralarda yer almasının faydalı bulunma durumunu negatif yönde etkilediğini belirtmiştir.

Çalışmada tespit edilen yorumların faydalı bulunma olasılığını etkileyen unsurlar yorum sitelerinin kullanıcılarına daha faydalı yorumlar oluşturması için bir kılavuz hazırlamasında kullanılabilir. Ayrıca faydalı oy kazanmak için yorumcuların resim paylaşması teşvik edilebilir.

Araştırmada kurulan lojistik regresyon, modeli yorumun faydalı bulunma olasıllı̆ındaki değişimin \%40,2 ile \%62,9'unu açıklayabilmektedir. Kullanılan değişkenlerle açıklanamayan kısmın metin madenciliği teknikleri kullanılarak yorumların ilgili oldukları konu başlıklarının da tespit edilerek analizlere dahil edildiği daha kapsamlı çalışmalarla açıklanması mümkün olabilir.

\section{KAYNAKÇA}

Ak, S. ve Kızılırmak, İ. (2019). Otel İşletmelerinde E-Şikâyetler ve E-Şikâyet Yönetimi Üzerine Bir Araştırma, Türk Turizm Araştırmaları Dergisi, 3(4): 820-832.

Ak, S. ve Dincer, M. Z. (2019). Investigation of Consumer Reviews on Social Media for Five-Star Hotel Enterprises in Istanbul: A Case of TripAdvisor, Journal of Tourismology, 5(2): 171-183.

Akgöz, E. ve Tengilimoğlu, E. (2015). Online Müşteri Değerlendirmelerinin, Tesis Özellikleri Açısından İncelenmesi; Booking.Com Örneği. 16. Ulusal Turizm Kongresi, 12-15 Kasım. Çanakkale. ss: 145-163.

Çetinkaya, F. Ö. ve Şahbaz, R. P. (2019). Sosyal Medyada Gelişmeleri Kaçırma Korkusunun Kişinin Tatil Satın Alma Niyetine Etkisi, Türk Turizm Araştırmaları Dergisi, 3(3): 383-402.

Dirsehan, T. (2016). An Application of Text Mining to Capture and Analyze eWOM: A Pilot Study on Tourism Sector. In Rathore, S. and Panwar, A. (Ed.) Capturing, Analyzing, and Managing Word of Mouth in the Digital Marketplace. (pp. 168-186). IGI Global, USA.

Eslami, S. P., Ghasemaghaei, M. and Hassanein, K. (2018). Which Online Reviews do Consumers Find Most Helpful? A Multi-Method Investigation, Decision Support Systems, 113(2018): 32-42. 
Fang, B., Ye, Q., Kucukusta, D. and Law, R. (2016). Analysis of The Perceived Value of Online Tourism Reviews: Influence of Readability and Reviewer Characteristics. Tourism Management, 52(2016): 498-506.

Filieri, R., McLeay, F. Tsui, B. and Lin, Z. (2018). Consumer Perceptions of Information Helpfulness and Determinants of Purchase Intention in Online Consumer Reviews of Services. Information \& Management, 55(2018): 956-970.

Filieri, R., Raguseo, E. and Vitari, C. (2018). When are Extreme Ratings More Helpful? Empirical Evidence on the Moderating Effects of Review Characteristics and Product Type. Computers in Human Behavior, 88(2018): 134-142.

Hong, H., Xu D., Wang, G. A. and Fan, W. (2017) Understanding the Determinants of Online Review Helpfulness: A Meta-Analytic Investigation. Decision Support Systems, 102(2017): 1-11

Hu, Y. H. and Chen, K. (2016). Predicting Hotel Review Helpfulness: The Impact of Review Visibility and Interaction Between Hotel Stars and Review Ratings. International Journal of Information Management, 36(2016): 929-944.

Hu, Y., H., Chen, Y., L. and Chou, H., L. (2017). Opinion Mining from Online Hotel Reviews -A Text Summarization Approach. Information Processing and Management, 53(2017): 436-449.

Huang, A. H., Chen, K., Yen, D. C. and Tran, T. P. (2015). A Study of Factors That Contribute to Online Review Helpfulness. Computers in Human Behavior, 48(2015): 17-27.

İslamoğlu, A. H. ve Alnıaçık, Ü. (2014). Sosyal bilimlerde araştırma yöntemleri. İstanbul: Beta Basım A. Ş.

Karimi, S. and Wang, F. (2017). Online Review Helpfulness: Impact of Reviewer Profile Image. Decision Support Systems, 96(2017): 39-48.

Lee, P. J., Hu, Y. H. and Lu, K. T. (2018). Assessing The Helpfulness of Online Hotel Reviews: A Classification-Based Approach. Telematics and Informatics, 35(2018): 436-445.

Kozak, R. ve Cingi, C. C. (2019). Çevrimiçi Platformların Konaklama Sektörüne Etkileri, Türk Turizm Araştırmalar Dergisi, 3(3): 174-187.

Liang, S., Schuckert, M. and Law, R. (2019). How to Improve the Stated Helpfulness of Hotel Reviews? A Multilevel Approach. International Journal of Contemporary Hospitality Management, 31(2): 953-977.

Liu, Z. and Park, S. (2015). What Makes a Useful Online Review? Implication for Travel Product Websites. Tourism Management, 47(2015): 140-151.

Malik, M. and Hussain, A. (2018). An Analysis of Review Content and Reviewer Variables that Contribute to Review Helpfulness. Information Processing and Management, 54(2018): 88-104.

Pan, Y. and Zhang, J.Q. (2011) Born Unequal: A Study of the Helpfulness of User-Generated Product Reviews, Journal of Retailing. 87(4): 598-612.

Park, S. and Nicolau J., L. (2015). Asymmetric Effects of Online Consumer Reviews. Annals of Tourism Research, 50(2015): 67-83.

Singh, J. P., Irani, S., Rana, N. P., Dwivedi, Y. K., Saumya, S. and Roy, P. K. (2017). Predicting the "Helpfulness" of Online Consumer Reviews. Journal of Business Research, 70(2017): 346-355.

Tengilimoğlu, E., Göral, R. ve Akgöz, E. (2017). Olumlu ve Olumsuz Geri Bildirimlerin Memnuniyet Düzeylerine Göre İncelenmesi: Booking.Com Örneği. 18. Ulusal Turizm Kongresi, 18-22 Ekim. Mardin. ss: 556-566. 
Wong, C. U. I. and Qi, S. (2017). Tracking the Evolution of a Destination's Image by Text-Mining Online Reviews - The Case of Macau. Tourism Management Perspectives, 23(2017): 19-29.

Wu, J. (2017). Review Popularity and Review Helpfulness: A Model for User Review Effectiveness. Decision Support Systems, 97(2017): 92-103.

Zhou, S. and Guo, B. (2017). The Order Effect on Online Review Helpfulness: A Social Influence Perspective. Decision Support Systems, 93(2017): 77-87. 